Homann, F. (2020): Las letras primitivas de los cantes a palo seco, tonás y martinetes: romances narrativos sobre la Prisión General de los Gitanos. Cultura, Lenguaje y Representación, Vol. XxIV, 89-104

ISSN $1697-7750 \cdot$ e-ISSN 2340-4981

DOI: http://dx.doi.org/10.6035/clr.2020.24.5

\title{
Las letras primitivas de los cantes a palo seco, tonás y martinetes: romances narrativos sobre la Prisión General de los Gitanos
}

The primitive lyrics of A cappella songs, tonás and martinetes: narrative romances about the Great Gypsy Round-up

\section{FLORIAN HOMANN}

UNIVERSITÄT ZU KÖLN/UNIVERSITÄT MÜNSTER

RESUMEN: En el mundo flamenco, existe la suposición de que los cantes flamencos contienen unas letras esencialmente líricas que no narran, sin embargo, hay ciertas modalidades, como los cantes a palo seco denominados tonás y martinetes, cuyos soportes literarios derivan de textos más largos y narrativos. Para demostrar que esta consideración es el resultado de un largo proceso de transformación, se analizan los escritos sobre tonás y martinetes y se compara el contenido de sus coplas con las descripciones de ciertos hechos históricos. En múltiples casos coinciden los fragmentos, aunque sean muy breves, con determinados acontecimientos reales, lo que se puede interpretar como un indicio de que las letras efectivamente derivan de unos textos de romances noticiosos, narrando sobre asuntos carcelarios y la persecución de los gitanos. Uno de los hechos concretos constituye la Prisión General de los Gitanos, realizada en 1749, incluyendo su preparación y sus consecuencias. Así, esta propuesta de buscar el origen de los martinetes, más que en una forma musical, en las letras primitivas, adopta la perspectiva de considerar a los martinetes unos cantos que se han originado como textos narrativos orales, compuestos por los mismos afectados de la medida política sobre la mitad del siglo XVIII y que posteriormente se han convertido, dentro del marco de la cristalización de la cultura musical del flamenco en el siglo XIX, en coplas musicales, asociadas a determinadas melodías del cante a palo seco.

Palabras clave: cantes a palo seco, flamenco, fragmentarismo, la Prisión General de Gitanos, martinetes, romancero, tonás.

ABSTRACT: Flamenco lyrics are said to be essentially non-narrative, but there are particular modalities like the A capella genres tonás and martinetes, whose original texts actually derive of large and narrative ballads. This contribution will show that the consideration of lack of narrative aspects is just the result of a long term process by analyzing the documents about tonás and martinetes and comparing the content of their lyrics with the descriptions of certain historical facts. The examples of analysed flamenco lyrics show that there are a lot of cases 
where the short text fragments coincide with the real events, which also indicates that these texts indeed stem from narrative and large romances, in the sense of epic based ballads with a relevant function as an oral form of news bulletin. As these texts relate about matters of prison and persecution of Spanish Roma, one of the concrete events that actually took place is the Great Gypsy Round-up in 1749, with its preparation and consequences. The origins of the martinetes are not mainly explained by the musical performance but by their first literary texts, originated as oral narrative ballads. So these martinetes must have been composed in the eighteenth century by the affected Spanish Roma, applying the techniques of oral-formulaic composition and using formulas of epic romances. Subsequently, in the nineteenth century with the crystallization of the former elements into flamenco culture, the texts were also transformed into short stanza, associated with certain musical aspects of these A capella songs.

Key words: A capella songs, flamenco, fragmentism, Great Gypsy Round-up, martinetes, romancero, tonás.

\section{LA CULTURA FLAMENCA Y LAS LETRAS DEL CANTE ${ }^{1}$}

El flamenco, cuyas tres facetas cante, toque y baile se dividen en numerosas modalidades distintas, denominadas palos y estilos, se define mayoritariamente por aspectos musicales. Un palo es una variante musical con características únicas y un estilo una forma específica de ejecutar esta modalidad. Durante mucho tiempo, para explicar los orígenes y la creación de esta manifestación artística, se ha buscado un origen único en una de estas modalidades de la que habrían derivado las demás, gracias a su mayor antigüedad. Es a partir de la década de los años 90 del siglo XX que las investigaciones científicas rebaten muchas creencias anteriores sobre el origen del cante, por lo que hoy en día hay consenso en que el flamenco constituye un fenómeno con muchas variedades legítimas distintas, surgido en el contexto sociocultural del siglo XIX ${ }^{2}$.

Así, se puede describir un desarrollo en distintas etapas y se puede hablar de una etapa preflamenca ${ }^{3}$, antes de cristalizarse las distintas manifestaciones musicales del protoflamenco en una cultura artística que se estableció en la Edad de Oro del flamenco, en la segunda parte del siglo XIX, en la que se hizo conocido en los cafés cantantes. En 1881 salió a la luz la primera colección de letras de cantes flamencos, recogidos y anotados por Antonio Machado y Álvarez, usando el seudónimo Demófilo, cuyo prólogo constituyó para mucho tiempo una fuente imprescindible para la cuestión. Hasta hoy el flamenco ha evolucionado, siguiendo diferentes etapas de desarrollo con una valoración cambiante de los distintos tipos. Dentro de la amplia gama actual, el cante cuenta con ciertos palos especialmente valorados, cuyas formas primitivas derivan de un fenómeno específico y es que los miembros de ciertas familias de las clases humildes de una región

\footnotetext{
${ }^{1}$ Esta investigación se ha realizado en el marco de un proyecto de tesis doctoral, realizado en la Universidad de Colonia en cotutela con la Universidad de Sevilla, con una estancia en Sevilla desde octubre de 2017 hasta abril de 2018, gracias a la financiación por parte del DAAD (German Academic Exchange Service).

2 Entre otras aportaciones destacan los trabajos que investigan sobre el flamenco desde una perspectiva sociológica, contextualizando sus orígenes en el ámbito socio-cultural del siglo XIX en Andalucía.

${ }^{3}$ Esta denominación parece la más adecuadas, después de que se han rebatido, o al menos, matizado las ideas de una etapa hermética, derivadas de la corriente del Mairenismo y expresando que los gitanos mantendrían su cante herméticamente en secreto (véase Mairena y Molina, 2004: 35-36).
} 
determinada en la Baja Andalucía interpretarían a su manera específica las manifestaciones existentes ya con anterioridad en el folklore andaluz. Estas consistían principalmente en el cancionero lírico popular y, con especial relevancia para este artículo, en el romancero tradicional (Suárez Ávila, 1989). La influencia del romancero se hace notar, ante todo, en las modalidades musicales denominadas cantes a palo seco.

\section{LOS CANTES A PALO SECO: TONÁS Y MARTINETES}

Con respecto a los cantes a palo seco se puede anticipar que estos constituyen una manifestación preflamenca que, al incorporarse a la emergente cultura flamenca, se ha transformado notablemente, constituyendo hoy una de sus manifestaciones más importantes y consideradas como una de las más auténticas. En general, este término denomina los cantes que se desarrollan sin acompañamiento instrumental de guitarra, $o$ sea a capela; una denominación alternativa para este subgrupo es la de las tonás -con su etimología en las tonadas de romances-, un término que, sin embargo, tiene distintas significaciones en la cultura flamenca ${ }^{4}$. Además de las que se tratan aquí, existen las tonás campesinas, como los cantes de trilla (Gómez, 2003: 37-57), y las saetas viejas, que asimismo derivaron de antiguos romances con un contenido religioso (Aguilar y Tejera, 1998). Los aspectos musicales son notablemente parecidos, no obstante, se notan diferencias cruciales en cuanto a los textos cantados y los contextos en los que se ejecutan estos cantes. Aquí se examinan los que se encuentran en una relación con la comunidad de los gitanos, los cuales cantan sus romances en unos contextos socioculturales específicos y, por lo tanto, con determinadas funciones simbólicas. Entre los romances entonados por gitanos también es necesario distinguir entre los que se cantan en ambientes o bien alegres - por ejemplo, los corridos de la boda gitana con sus correspondientes connotaciones- o bien tristes - los que interesan aquí, especialmente los titulados como martinetes-.

\subsection{LAS LETRAS TRADICIONALES DE LOS MARTINETES PRIMITIVOS: ROMANCES SOBRE ASUNTOS PRISIONEROS}

A los martinetes se atribuye un origen misterioso, enigma reforzado por una cita ambigua de Demófilo, ubicando la ejecución de estos cantes entre las fraguas y las cárceles, cuya interpretación creó muchas confusiones y llegó a considerar los martinetes como un cante herrero, creado simplemente para acompañar el trabajo en las fraguas.

Los martinetes o carceleras, llamadas de todos modos, según unos, porque se cantan al son de los martillos en las fraguas, y según otros, por ser propios de los presidiarios, son también coplas de cuatro versos romanceados [...] y, por lo general, forman trovos, cuyo asunto es el llorar, mejor que cantar, las fatigas, trabajos y los tormentos y durísimos castigos que pasan los pobres presos, condenados a cadena y a otras penas análogas.

(Machado y Álvarez, 1996: 85-86)

\footnotetext{
${ }^{4}$ Hay flamencólogos que usan el término tonás en este sentido, como grupo de cantes que contiene los martinetes, carceleras, saetas y deblas (Cenizo, 2009: 21) -en otras palabras: «martinetes, carceleras y deblas son un mismo cante, variantes temáticas y melódicas de un palo general denominado toná» (Cáceres y Del Campo, 2013: 460)-, mientras que otros describen con este término un propio tipo de cante que, a su vez, se puede distinguir en hasta 30 maneras distintas de ejecución musical, interpretando de tal manera una declaración del informante Juanelo de Antonio Machado y Álvarez, quien habló de unas 30 tonás diferentes. Por esto, Demófilo dedicó a las tonás un apartado propio, separándolas de los martinetes, sinónimo de las carceleras, y de las deblas.
} 
A partir de las reflexiones de Demófilo, considerando los términos gitano y flamenco como sinónimos, se desarrollaba una teoría romántica del cante, según la cual estos cantes a palo seco serían el arquetipo del auténtico cante gitano. En esta línea, la «flamencología tradicional» (Steingress, 2005: 111) sostenía que los gitanos procedentes de la India mantendrían su música en secreto en su hogar y las fraguas, rodeando para esto «el mundo de la herrería de un aura romántica que ha servido para justificar un origen exclusivamente gitano de los cantes» (Campo y Cáceres, 2013: 446). Antonio Mairena, haciendo un gran esfuerzo musical para recuperar la gama amplia de antiguas tonás en los años 60, defendía en su libro con Ricardo Molina que los palos matrices del cante fueron generados por creadores gitanos, argumentando que ciertos individuos pertenecientes a esta etnia eran los únicos ejecutantes que fueron mencionados en los testimonios literarios. De acuerdo con las ideas de Demófilo, durante mucho tiempo se ponía un enfoque exclusivo en la ejecución musical de los cantes, con unos sonidos arcaicos que sólo los gitanos podrían custodiar en el hermetismo de sus familias ${ }^{5}$. Además, se trazaba una dicotomía temática y estilística entre letras andaluzas y letras gitanas, subrayando Molina y Mairena (2004: 99-126) la subjetividad del Yo gitano, expresando la queja y el dolor específicamente gitanos. Hasta hoy se puede observar que se suele tratar en los cantes por tonás o martinetes con frecuencia un tema que es «el sino gitano» (Vadillo, 2015: 138).

En fechas recientes, Cáceres y Del Campo (2013) desmitifican los orígenes de los martinetes y demuestran que su origen no se encuentra directamente en las fraguas, en las que, no obstante, también se pueden haber transmitido, además de otros tipos de cantes. El principal argumento en contra de la teoría de la génesis del cante para el acompañamiento del trabajo de herrería es la complejidad de su codificación musical, al menos de la actual ${ }^{6}$.

Sin embargo, los estudios recientes de ninguna forma niegan que se trata de un cante en estrecha relación con el romancero, lo que causa nuevas complejidades. A primera vista, los martinetes no consisten a nivel literario en poemas largos coherentes sino en estrofas aisladas, los cuatro versos romanceados de los que habló Demófilo, que se combinan en cada performance: según la composición por aspectos musicales, la estructura hoy es usualmente de tres coplas sueltas ABC (Martín, 2011: 187).

No obstante, los puntos centrales en los que creo necesario matizar para indagar en los orígenes de estos cantes son, por un lado, el enfoque exclusivo en la ejecución musical, sin contradecir que los aspectos musicales jueguen un papel crucial en el flamenco, y, en segundo lugar, la suposición de la independencia original de cada copla suelta como unidad musical por sí. En cambio, parto de la hipótesis de que los martinetes primitivos eran textos narrativos, largos y coherentes -en una palabra: romances- que se trasformaron significativamente durante el siglo XIX, con la gestación de la música flamenca, en estrofas líricas autónomas.

Ya se puede desprender de la cita presentada que las coplas formarían, por lo general, unos trovos, se trata de un término con el que Demófilo se refería a los textos de varias estrofas enlazadas: «corridos de tres, cuatro y cinco coplas que vienen a formar, por decirlo así, pequeños trovos en los que se conservan hechos particulares que aún viven algunos en la memoria de los cantadores» (Machado y Álvarez, 1996: 231). En esta línea, es un detalle nada desestimable que este recopilador ya ordenó sus martinetes en dos

\footnotetext{
${ }^{5}$ El concepto de Razón Incorpórea, desarrollado posteriormente, implica que la música que se relaciona con el concepto del cante gitano-andaluz puro sería ininteligible e intransmisible fuera del colectivo gitano. 6 Para unos análisis detallados de los aspectos musicales, véase las investigaciones de Mora et al. (2010), Martín (2011), Castro (2010) y Vadillo (2015: 137-139), entre otros.
} 
apartados, por un lado, los que ya realmente formaron coplas autónomas y, por otro lado, dichos relatos poliestróficos, cuyas cuartetas mantienen una relación la una con la otra.

En su diccionario, Gamboa y Núñez (2007: 356, enlace en el original) usan los nombres carceleras y martinetes como sinónimos y refieren al hecho de que los textos son cantados con cierta coherencia narrativa en determinadas regiones de la geografía flamenca: «Existen en la zona de Los Puertos unos antiguos martinetes-corridos ( carceleras), que se decían consecutivamente, tomándole el pie un cantaor a otro, y que siguen un triste argumento carcelario». Es significativo en este contexto que el término corrido se usa como sinónimo para un romance cantado de forma completa (Suárez Ávila, 1989: 599). Es decir, existían y todavía existen textos de martinetes que pueden contener en su unidad musical más de una copla aislada y que presentan cierta narratividad. En resumen, se puede partir de que martinetes y carceleras designan el mismo fenómeno, que consiste en una interpretación específica de romances narrativos con un argumento prisionero. Efectivamente, 25 de los 49 textos de los martinetes presentados por Demófilo hasta 1881 contienen una temática carcelera y una mención explícita de la cárcel o del calabozo aparece en diez de sus textos recolectados, subrayando el mismo recolector la importancia del asunto prisionero (Machado y Álvarez, 1996: 231). Y es que Molina y Mairena (2004: 165) anotan que «el tema de la cárcel no es privativo de la carcelera, sino común a las tonás en general», ante todo, las que se suelen ejecutar por gitanos.

Demófilo, partiendo de la idea de una relación inseparable entre el colectivo gitano y los cantes flamencos, observó además que los martinetes cuentan con numerosos gitanismos y que «se cantan ya, a excepción de los lugares en que se crean, bastante poco» (Machado y Álvarez, 1996: 86). Así, estos cantes se describen acertadamente en estrecha relación con el colectivo gitano y, al contrario del siglo XX en el que volvieron a constituir por su carácter primitivo y atribuido a lo gitano una modalidad central del cante, a finales del siglo XIX se cantaban escasamente, lo que lleva también a una escasez de informantes disponibles a transmitir sus letras, «aunque la música de los martinetes es bastante bella y melancólica y muy propia del carácter y gusto de los gitanos» (Machado y Álvarez, 1996: 223). Algunas opiniones del folklorista sevillano, generando ciertos mitos al ser aplicada la teoría del origen gitano a todos los palos básicos del flamenco, se hicieron discutibles en el tiempo en que la «investigación científica del flamenco» (Steingress, 2005: 120) remontó la adscripción exclusiva del cante al colectivo gitano. Sin embargo, estas observaciones, con respecto a los martinetes en particular, no necesitan ser desmentidas, a pesar de que se puede debatir de nuevo sobre su interpretación. La interpretación clásica de estas declaraciones consistía en que los cantes a palo seco como verdadero cante gitano antiguo $-\mathrm{y}$, por tanto, difícil en su ejecución musical-, se encontrarían en peligro, debido a su escaso cultivo. De ahí que los intelectuales, flamencólogos y artistas del siglo XX querían recuperar estas modalidades, cuyo carácter primitivo les proporcionaría su jondura original y pureza no comercial, como palos centrales del cante auténtico. Sin embargo, sostengo que lo dicho sobre la escasa ejecución en su momento ocurre no primordialmente por ser la interpretación muy difícil a nivel musical sino por una función específica que no hacía los martinetes y las tonás muy atractivos para una interpretación en los cafés cantantes de la época, ofreciendo espectáculos de cante y baile a todo tipo de público. Esta función es la de narrar, mediante la recitación de unos textos realmente largos en una tonada monótona y primitiva, para mantener viva la memoria colectiva a determinados hechos históricos, con estos relatos recitados sin más acompañamiento musical. Y es que todavía se nota en algunos casos esta narratividad de las letras, que recuerdan a narraciones largas, incluso en prosa: «A 
veces, como en las viejas tonás, se tiene la impresión de lo que oímos es prosa cantada» (Caballero Bonald, 2004: 587) ${ }^{7}$.

Según esta argumentación, resultará lógico que las tonás y martinetes tengan esta estrecha vinculación con la etnia gitana, simplemente porque se trata de romances narrativos cantados por los calés. Los estudiosos que matizaron las ideas sobre la relación entre cultura flamenca y gitanos, desde una perspectiva sociológica, nunca contradijeron al hecho de que los gitanos transmitieron una multitud de romances (Steingress, 2005: 255), sino que reafirmaron en cambio que la mayor parte de las coplas de tonás derivan efectivamente de romances fragmentados, como lo defiende García Gómez (1993: 197198). Así mismo, Cruces (2004: 604) apunta que «muchas tonás son desgajamientos de los antiguos romances, que -como los pregones- forman parte de una tradición literaria de corridos demasiado largos para ser recordados, y a cuyos pedazos se le imprimió un rajo flamenco». Es decir, en cuanto a las raíces y los orígenes de determinados palos básicos flamencos, los gitanos destacaban más bien como transmisores de romances y no es que crearan una nueva música desde la nada, sino que transmitieron los textos romancísticos existentes en sus propias tonadas, por lo que seleccionaron las partes más aptas de los textos existentes para sus necesidades expresivas.

\subsection{EL FRAGMENTARISMO DE LOS TEXTOS NARRATIVOS Y EL DESARROLLO A LAS COPLAS SUELTAS}

Frente a la narratividad del texto épico, presente en el romancero, se evidencia el lirismo de las letras flamencas, resaltado por cuantos se acercan a la poesía del cante. Las letras formarían ya en la opinión de Demófilo un «género poético, predominantemente lírico» (Machado y Álvarez, 1996, 78). Así, en el mundo flamenco se da por hecho que las coplas sueltas no narran más allá de la unidad cerrada, partiendo Núñez (2011) de una principal «inconexión temática entre las diferentes letras de un cante». Sin embargo, esta consideración actual, en muchos casos, no es sino el resultado de un proceso largo de transformaciones de los soportes literarios, desde una base de romances preflamencos hasta las coplas flamencas esencialmente líricas que emplean los cantaores hoy.

En cambio, el romancero como género de literatura oral es narrativo por definición, a pesar de ser transmitidos sus textos de forma cantada: «Los romances son poemas narrativos» (Díaz-Mas, 2008: 116). No se puede olvidar que en general todos romances, en su función original, no eran otra cosa que textos noticiosos. No en vano, Piñero (2001: 100) declara con respecto a los romances fronterizos medievales que se solían componer «al calor de los acontecimientos» con el «hecho histórico como punto de partida del texto poético». Este detalle resultará de especial relevancia para comprender los textos primitivos de tonás y martinetes, considerados aquí como manifestaciones preflamencas.

Un punto de debate sobre el origen del flamenco consiste en si se puede datar su creación sobre los finales del XVIII o sobre la mitad del XIX. Mientras que la datación posterior es fundada en la primera mención del término flamenco en unos periódicos en 1853, la ubicación temporal en una fecha aproximada al año 1770 es basada en el argumento de que en esta época viviría en Jerez de la Frontera el aguador gitano Luis Montoya Garcés, apodado Tío Luis el de la Juliana, cuya existencia queda confirmada hoy (Castaño, 2007: 53-60). Esta figura mencionada en el prólogo de Demófilo era

\footnotetext{
${ }^{7}$ El mismo término de la prosa cantada lo usó ya Federico García Lorca con respecto al cante jondo, «aunque en realidad son tercetos o cuartetos asonantados sus textos literarios» (García Lorca, 1984: 5657).
} 
conocido por cantar tonás y otros cantos en directa relación con el romancero y, por lo tanto, es considerado en muchas fuentes bibliográficas como el primer cantaor flamenco (Blas Vega \& Ríos Ruiz, 1988: 753). Para solucionar esta cuestión, se puede partir de que, si el flamenco propiamente dicho se cristaliza en el siglo XIX, los mencionados cantos preflamencos del siglo anterior no corresponden exactamente a lo que hoy se entiende por palos flamencos, definidos según sus aspectos musicales, sino que serían más bien un tipo específico de romances narrativos, cultivados de especial manera por el colectivo transmisor de los gitanos.

Una circunstancia relevante para la transformación de los cantos es que, en el siglo XIX, se nota en el ámbito cultural general cierta gitanofilia (Cantos, 1996). Este hecho se puede explicar con la tendencia que tanto los majos como la figura del gitano fueron exaltados en muchas manifestaciones artísticas, bajo la influencia del movimiento de la afición, surgido ya a finales del siglo anterior por la intervención de individuos no gitanos de las clases sociales media y alta que recrearon artificialmente esta subcultura, relacionada con las capas sociales bajas y los bohemios (García Gómez, 1993: 15, 51). Así, durante la época del costumbrismo, cuando lo andaluz estaba en boga como tema literario, pictórico y musical, se evidencia de nuevo esta exaltación de las tradiciones y la música a lo popular, asociadas a su vez con lo gitano, elementos que se usaron para proyectar los valores tradicionales españoles. Steingress (2005: 297) deduce de esto que se construye el flamenco, al menos en parte, como una cultura bohemia agitanada.

A continuación, estos cantos atribuidos a los gitanos se desarrollan de tal manera que se va perdiendo paulatinamente el enfoque en sus aspectos textuales, ya que, en la emergente cultura flamenca, representada en espectáculos públicos de baile y cante, se hacen más importantes los aspectos musicales y se suele conceder «más importancia al alarido que a la letra en sí misma» (Castaño, 2007: 31). Este proceso va de la mano con la preferencia de la copla breve y lírica, frente al poema épico y narrativo, observable en el romanticismo dieciochesco (Baltanás, 2005: XXVI). Además, desde el siglo XIX se ha desarrollado la creencia de que la música puede transportar la memoria colectiva de una comunidad; estas ideas de la evocación de experiencias pasadas a través de ciertas melodías van acorde con los pensamientos del romanticismo, cuya estética se fundamenta en el sentimiento y la emoción (Mendoza, 2014: 114). Por lo tanto, la figura artística del gitano podía representar con su música perfectamente estas emociones para satisfacer las expectativas del público de la época.

Siguiendo estas tendencias, los textos que se usan en los cantes cambian la perspectiva de enunciación desde la habitual tercera persona, relacionada con una manera descriptiva, hacia la primera persona, esencialmente lírica y subjetiva. Frente a los romances épicos, se convierten los textos flamencos en cosa bien distinta, lo que hoy dificulta el reconocimiento de su origen: «es preciso conocer a fondo el romancero oral, para sorprender, en medio de una serie de bulerías por soleá, o en medio de unas letras de tonás, fragmentos, que, trasegados en la tradición, se han convertido en otra cosa» (Suárez Ávila, 2008: 6).

Se desarrolla un fuerte fragmentarismo en las letras del flamenco en general y la base de romances preflamencos se ve convertida en coplas sueltas en múltiples modalidades musicales como, por ejemplo, las bulerías. Suárez Ávila (2004: 16), explicando detalladamente su teoría del origen romancístico de este palo más bien alegre, declara que sus principales soportes literarios serían unos fragmentos de romances burlescos, juntos a diversas canciones líricas con un tono erótico y picaresco. En sus estudios de campo sobre los romances entonados por gitanos flamencos, tanto Bonet y Ruiz (1989) en Jerez como Baltanás y Pérez Castellano (1989) en la provincia de Sevilla informan sobre la impresión de que sus informantes no solían cantar los textos 
romancísticos de forma corrida, sino que estos investigadores han podido recoger en su mayoría fragmentos independizados y cantados por bulerías.

En esta línea, Zoido (2004: 649) observa acertadamente: «Sin ser conscientes de ello, las voces de los cantaores desgranan aún muchas estrofas que la fragilidad de la memoria desgajó de un corpus inmenso y que convirtieron en coplas independientes las veleidades de las modas». En adición a esto, hay que anotar que la razón para el desgajamiento no es sólo la fragilidad de la memoria biológica individual del que canta, sino que el cantaor elige para el cante lo más relevante de lo que se recuerda en la memoria flamenca, o sea, el cantaor realiza su selección de los fragmentos según los aspectos musicales y según las expectativas del público.

En resumen, se hace notar la preferencia de los flamencos por las breves coplas sueltas, altamente densas y cargadas de valor simbólico. De acuerdo con esta evolución en general, también los cantes a palo seco, al incorporarse como modalidades en la cultura flamenca, se transforman paulatinamente en géneros musicales, sin que fuera necesario entre los portadores de la tradición saber qué era exactamente lo que comunicaran los textos originales, en principio narrativos. De esta manera se puede explicar la evolución de los textos de los martinetes, desde su forma original de romances hasta las cuartetas romanceadas de las que ya habló Demófilo.

En consecuencia, se perdió la conciencia sobre el contenido textual de los primitivos cantes a palo seco, tonás y martinetes, narrando sobre acontecimientos en relación con prisiones y cárceles. Campo y Cáceres vuelven a anotar que la peculiaridad de las tonás deriva de este hecho de que son en realidad fragmentos de textos romancísticos y narrativos sobre ciertos asuntos carcelarios:

La raíz romancística de las tonás explicaría que estos cantes presenten, pese a su temática triste -común a otros cantes flamencos-, claras diferencias con otros palos. Así, frente a la más lírica seguiriya, las tonás son narrativas. Por otra parte no expresan la angustia existencial o amorosa, como es común en las seguiriyas, sino la queja por las condiciones de vida. La peculiaridad temática de las tonás respondería a un proceso de selección con respecto a los romances, escogiendo las partes que harían alusión a cárceles o persecuciones.

(Del Campo y Cáceres, 2013: 461)

La noción de dicho proceso de selección, en directa relación con el fragmentarismo, resulta fundamental para comprender la evolución de los cantes a palo seco. Juanelo, el informante de Demófilo, habló de una toná de los pajaritos y de su adscripción al ya mencionado Tío Luis el de la Juliana (Machado y Álvarez, 1996: 245). Al respecto, parece acertada la opinión de Suárez Ávila (1989: 603) quien declara que esta toná de los pajaritos es simplemente un trozo de texto extraído del romance El Prisionero del ciclo de Bernardo del Carpio, frecuentemente recitado entre los gitanos flamencos. Y es que en las versiones gitano-andaluzas del romance se manifiestan en la mayoría de las versiones unos versos sobre tres pájaros a los que escucha el sujeto enunciador, encerrado en una torre sin ventanas, cuyo canto le avisa sobre si es de día o de noche (Robertson, 1989: 612). Es decir, se trata de una fórmula textual, adecuada para ser insertada en unos textos narrativos, expresando las circunstancias de una prisión, que como estrofa aislada le dio el nombre al cante.

\section{LA PERSECUCIÓN Y LA PRISIÓN GENERAL DE LOS GITANOS EN EL SIGLO XVIII}

Desafortunadamente, hubo en el siglo XVIII un hecho trágico que merecía ser objeto de noticias y narraciones transmitidas en romances cantados: se trata de la Prisión 
General de los Gitanos (Martínez, 2014; Zoido, 2009) o Gran Redada (Gómez Alfaro, 1993) en 1749. Esta medida fue la culminación de una política represiva, seguida ya desde una primera pragmática de 1499 a la que siguieron varias más para someter los miembros del colectivo heterogéneo denominado gitano a una integración forzada en la sociedad de la época. En principio, respondió a la dificultad de poder controlar los individuos no asentados: sin realmente distinguir entre los que verdaderamente eran gitanos y los vagabundos no gitanos, el principal objetivo fue eliminar el nomadismo de los grupos considerados antisociales. En los siglos anteriores al XVIII, las pragmáticas proclamadas no consiguieron el éxito esperado, por lo que la política antigitana se agravó a inicios del siglo con la subida al poder de los monarcas de la casa borbón y la creación de una Junta de Gitanos en 1721. Tras asignarles a los gitanos sólo ciertos municipios donde poder vivir, se ejecutó la medida finalmente bajo el reinado de Fernando VI, planificada en secreto por Gaspar Vázquez Tablada y el Marqués de la Ensenada, Zenón de Somodevilla y Bengoechea. No obstante, la imposibilidad de definir exactamente lo que se buscaba provocó que durante la búsqueda de delincuentes potenciales se aprisionaron también muchos gitanos asentados e integrados, que después se tuvieron que dejar en libertad en un proceso largo (Martínez 2014: 29-44); los consiguientes problemas logísticos causaron, entre otras razones, el fracaso del "proyecto de exterminio" del "problema gitano" (citado en Martínez, 2014: 141), en las palabras del discurso oficial. Este fracaso y la situación caótica sirven también de explicación para la prohibición del término gitano en 1873, en una pragmática de Carlos III, y su borradura de todos los papeles oficiales para dejar caer en el olvido el desastre provocado.

Así, el acontecimiento fue olvidado durante siglos y sólo se ha vuelto a estudiar desde los años 1990, siendo Antonio Zoido (1999) el primero en relacionar explícitamente este hecho con los orígenes de lo flamenco. Si consideramos este acontecimiento y la única posibilidad para los gitanos, con su cultura entonces todavía ágrafa, de transmitir las narraciones sobre los hechos históricos en romances orales, resulta posible comprender por qué las letras primitivas de tonás y martinetes se relacionan tan inseparablemente, además de con los gitanos, con el tema carcelero. Se pueden encontrar múltiples ejemplos de coplas flamencas en las que han sobrevivido indicios sobre esta medida política.

Esta medida consistía en dos operaciones, de los cuales la principal se realizó por el ejército en la noche del 30 de julio 1749 hasta la madrugada del día siguiente, planeada en secreto para sorprender los gitanos durmiendo (Martínez, 2014: 28). Incontables son las alusiones a las horas de la noche, que se encuentran en los textos de los cantes a palo seco, lo que se refleja ya en muchos títulos, como el de las tonás «Las doce acaban de dar», entonadas por Camarón de la Isla en el álbum Caminito De Totana.

Además, la onomatopeya 'trin, trin, trán', más que frecuente para empezar estos cantes, se puede relacionar con las detenciones. Hasta hace poco, su uso se explicaba de manera simplista con la asociación del sonido a unos yunques, por haberse asignado a los martinetes exclusivamente la característica de cantes de fragua. Se trata de una hipótesis discutida, aunque sea extendida en múltiples vídeos y libros sobre el flamenco. Siguiendo la teoría recientemente matizada de buscar el origen de los martinetes no directamente en las fraguas sino en estrecha relación con el romancero (Del Campo y Cáceres, 2013), se puede basar en que esta onomatopeya, más que representar los golpes de los martillos, proviene del ruido provocado por alguien tocando la puerta, dado que se combina con frecuencia con el verso 'a la puerta llaman'. Se evidencia en la cuarta copla de los 
martinetes que hace Oliver de Triana ${ }^{8}$, en el capítulo dedicado a este cantaor en la serie televisiva Rito y Geografia del Cante:

Trin, trin, que a la puerta llaman

madre, yo no quiero abrir

madre, si será la guardia

madre, que vendrá a por mí.

Como sostiene Suárez Ávila (2003: 79), se trata de una fórmula compartida del romancero y constituye uno de estos elementos característicos usados para templarse en todas las tonás, según los informantes suyos. En realidad, son de hecho los primeros cuatro hemistiquios extraídos de una versión específica del Romance de Bernal Francés: es más que llamativa la semejanza del contenido de múltiples martinetes, en los que la llamada a la puerta suele traer consecuencias exclusivamente negativas, con la versión de este romance que presentan Piñero et al. (2013: 252), cuyo inicio dice: «Tras, tan, a la puerta llaman, tras, tan, yo no quiero abrir; tras, tan, si será la muerte, tras, tan, que vendrá por mí...». Es evidente que esta copla no se limita a su uso en el flamenco. En el romancero infantil encontramos versiones muy cercanas a las significaciones que puede expresar este inicio. Ruiz (2019: 229-231), especialista en el romancero jerezano, proporciona múltiples ejemplos en los cuales los transmisores aislaron de la misma manera los cuatro primeros hemistiquios del texto romancístico, usándolos como símbolos con una carga semántica negativa -o bien de una detención o bien directamente de la muerte-, y de los que uno mantiene incluso la onomatopeya en la forma «Tin, tin, llaman a la puerta» (Ruiz, 2019: 229), testimonio ya publicado por Mila y Fontanals en 1890.

En los cantes a palo seco flamencos, el símbolo, incorporado del cancionero popular general y adaptado a las necesidades expresivas de los transmisores, contiene valores semánticos semejantes. La referencia a ciertas horas de la noche en combinación con la agorera llamada queda evidente también en una estrofa de unos martinetes que he podido registrar al cantaor David Carpio ${ }^{9}$ el día 30 de abril de 2017 en Jerez de la Frontera, a pesar de que en este caso describe una versión actualizada de una detención, ejecutada efectivamente por la Guardia Civil:

Y eran las dos de la noche

y a mi puertecita llamaron,

el comandante de los civiles

y a mi padrecito se lo llevaron.

El Lebrijano canta en Rito y Geografía del Cante, en un capítulo dedicado a él, sus martinetes con una secuencia narrativa y la alusión mencionada a las horas de la madrugada:

Trin, trin, que a la puerta llaman,

trin, trin, que ya están abriendo:

serían las cuatro de la mañana

y mi madre a mí me encontró

y a mí me dijo:

¡Hijo mío de mis entrañas!

\footnotetext{
${ }^{8}$ A pesar de no pertenecer a la etnia gitana, se subraya en este capítulo su sabiduría de los cantes antiguos atribuidos a los calés, cantes a los que ha aprendido de una tradición oral inmediata en su barrio, indudablemente famoso por un tipo de flamenco ejecutado por transmisores gitanos.

${ }^{9}$ El nombre artístico de este cantaor nos recuerda además que existe una familia cantaora de gran tradición en Jerez con el apellido Carpio, lo que corresponde obviamente al hábito de los gitanos bajoandaluces, como transmisores destacados del romancero tradicional, de poner a sus hijos el nombre Bernardo del Carpio, protagonista de un ciclo de romances muy populares, desde los Siglos de Oro (Suárez Ávila, 1994).
} 
y la carita me la limpió.

Antonio Mairena también inicia con la llamada a la puerta tanto sus martinetes en el capítulo «La casa de los Mairena» de la misma serie Rito y Geografía del Cante como las tonás «Ni la luz del día» de la antología Medio siglo de cante flamenco, en el último caso sigue con estos versos de tema carcelero:
A la puerta llaman
no sé quién será.
A mí me metieron
en un calabozo
donde yo no veía
ni la luz del día...

A pesar de poder contar con estos indicios dispersos, bien es cierto que resulta muy difícil reconocer con exactitud los hechos concretos del siglo XVIII en los testimonios ambiguos que han sobrevivido hasta hoy, ya que proporcionan escasos datos concretos y suelen carecer de indicaciones de lugares o años. El hecho de que estos textos cantados hoy en día son sólo trozos cortos de unos romances largos queda subrayado por Zoido (2009: 164), quien está «convencido de que muchas de estas coplas formarían parte de composiciones más largas, como romances o seguidillas, y que, después, se fueron partiendo: es un proceso que afecta a buena parte de nuestros folclores (el flamenco y el otro) en todos sus terrenos». El mismo historiador reconoce las consecuencias problemáticas de los mencionados procesos de fragmentación, causados por la tradición oral: "es verdad que en el caso de la literatura tradicional, estas estrofas pueden ser aplicadas a diversos acontecimientos, oscureciéndose entonces su origen y, por tanto, su primera intención» (Zoido, 2009: 166).

De todas formas, bien pueden tener estas coplas sus antecedentes en unos textos noticiosos más largos sobre la Prisión General, en la que la detención era ejecutada por los militares. En los martinetes recogidos por Demófilo, tanto los presuntamente autónomos como los corridos, quedan como testimonios de la mencionada operación y de sus ejecutores militares las menciones de un generá, en el $\mathrm{n}^{\circ} 19$, los jundanales, en el $\mathrm{n}^{\mathrm{o}} 48, \mathrm{y}$, sobre todo, los sordaos, tanto los del $\mathrm{n}^{\mathrm{O}} 30$ como los 150 soldados escogidos que ha pedido el gobernador al general para estar «a la puerta e la carse», en el martinete $\mathrm{n}^{\circ} 4$ (Machado y Álvarez, 1996: 233, 237, 239, 242). Se puede suponer que estos 150 militares se necesitaban para deportar la misma cantidad de gitanos varones en una deportación a la que se alude con unos versos famosos, presentes en la colección demofiliana como martinete corrido $\mathrm{n}^{0} 7$ (Machado y Álvarez, 1996: 234-235) y como copla suelta recogida por Fernández Bañuls y Pérez Orozco (2004: 149):
A ciento cincuenta hombres
nos llevan a La Carraca
y allí nos dan por castigo
de llevar pieras p'al agua.

Este texto corresponde con los hechos ocurridos durante la Prisión General. Tras su deportación, desde la primera reclusión en una cárcel sevillana, el destino de la mayoría de los varones detenidos en Andalucía constituía unas cárceles improvisadas en Cádiz, antes de trasladar los que se consideraban aptos para el trabajo forzado al arsenal marino La Carraca en San Fernando (Martínez, 2014: 55-59). Uno de los motivos para la Prisión General, aparte del etnocidio planeado, consistía en aprovechar las manos de obra gratuitas en los trabajos de reconstrucción de la marina que nadie más quería realizar (Gómez Alfaro, 1993: 77; Zoido, 2009: 139; Martínez, 2014: 49). 
Queda sin duda que en el transcurso de la operación compleja había un último momento de despedida entre varones y mujeres -llevándose las madres a sus niños menores de siete años-, lleno de anécdotas dramáticas (Zoido, 1999: 202), ya que una idea principal de la Prisión General consistía en separar por sexo los miembros de la etnia para evitar su procreación. Bastante conocida es esta copla, entonada en una combinación curiosa con otra estrofa por Juan Talega, en sus martinetes del álbum Los cantes inéditos:

Sentadito estaba yo en mi petate

con la cabeza echada para atrás

yo me acordaba de mis niños,

mi madre ¿cómo estará?

Me llevaban a mí en conducción

y yo le dije a la partida

que me aflojaran a mí los cordeles

que los brazos a mí me dolían.

Para fundamentar sus argumentos de que estas letras se recitarían en referencia a los acontecimientos de 1749, Zoido (2009: 164-171) presenta diversas coplas más en las que pueden verse reflejados los hechos históricos, por ejemplo, refiere al texto del martinete $\mathrm{n}^{\circ} 49$ recogido por Demófilo (Machado y Álvarez, 1996: 201-202), en el que ha sobrevivido la indicación de un lugar concreto en la ciudad de Sevilla:

Ya los sacan e la carse

los sacan por el Baratiyo

e sentimiento yoraban

hombres, mujeres y niños.

Llama la atención que el hecho de sacar los detenidos de la cárcel no causa ninguna alegría sino todo lo contrario. Otro lugar concreto de Sevilla se encuentra en los martinetes de varias estrofas coherentes de los que habla el cantaor Naranjito de Triana -quien, aunque no pertenecía a la etnia gitana, conocía bien sus cantes- en la siguiente cita y que se transmitieron por tradición oral en su familia:

Solía hacer también que me gustaba mucho; lo había aprendido de mi padre. Era un martinete romanceao, o sea, que son tres letras que guardan relación, y son distintas melodías. Las dos primeras letras decían:

Estando yo en el Altozano

comiendo los míos piñones,

oí una voz que decía:

tira por los callejones.

Unos le tiraban piedras

y otros le pegaban palos,

oí una voz que decía:

No pegarle que es mi hermano.

Y después venía el martinete de remate:

Barquerito, barquerito, páseme usted al otro lao que me vienen persiguiendo de marina los sordaos.

(citado en Navarro \& Trigo 1993: 31, cursivas en el original) 
La detención de unos individuos en el Altozano, en el lado trianero del río, se conecta con la solicitud de ayuda al barquero para refugiarse al otro lado, a la ciudad de Sevilla. Los lugares sevillanos, sobre todo La Cartuja, aparecen también en las coplas recogidas por Demófilo y pueden interpretarse como indicios para el hecho de que los gitanos que vivían en las chozas en las afueras de Triana intentaban salvarse del cerco de la ciudad, a pesar de que dos o tres - las cifras varían según los testimonios- fueron matados en sus fugas (Zoido, 1999: 155-159). Además, la fórmula de que al narrador le persiguen los soldados corresponde con la detención de los gitanos por los militares. De nuevo remito a la omnipresencia de los sordaos en los martinetes presentados por Demófilo. El Altozano es uno de estos lugares concretos que vuelven a aparecer en varias letras arquetípicas de los cantes a palo seco. Espejo Arrebola (2011: 29) presenta como modelo típico de letras de tonás una versión de tradición oral llamativamente híbrida, con su mescolanza de segmentos distintos:

Los sacaron en conducción

y a la honra de los gitanos,

y los maltratan sin razón

y en medio del Altozano.

En definitiva, no resulta arriesgado relacionar las múltiples coplas de tonás y martinetes sobre una conducción con la deportación realmente ocurrida de los gitanos detenidos en la Prisión General a sus destinos respectivos, de los que uno de los más importantes constituye La Carraca (Zoido, 2009: 140). Martínez (2014: 55-59) describe el trabajo en este arsenal marino en su primera fase de construcción desde 1717, en un terreno fangoso, inestable y de ninguna consistencia. Para los forzados, «metidos en agua hasta la cintura» (Zoido, 1999: 168), la principal tarea consistía primero en la reedificación del muelle, durante varios decenios tras una inundación en 1737 hasta que, después de la supresión del servicio de las galeras en 1748, pasarían todos a reforzar el estacado realizado. La construcción de cada astillero exigía más de cuatro mil estacas clavadas a través de aparatos denominados efectivamente martinetes, funcionando estos mediante las caídas repetidas de un peso alzado a fuerza de brazos de unos 20 peones. Del Campo y Cáceres (2013: 459-460), negando el uso frecuente del término para referirse a los martillos con que trabajan los herreros en las fraguas, declaran que «el martinete se refiere a los grandes martillos hidráulicos de las ferrerías preindustriales que empiezan a generalizarse en el siglo XVIII y, por extensión, a estos establecimientos industriales. Finalmente designa a una máquina empleada para clavar estacas». Las consecuencias de las connotaciones negativas del término martinetes se evidencian a nivel metafórico, según lo que en «La génesis de martinete I» opina Lefranc ( $\sin$ año): «Para esos forzados encadenados el martinete fue el instrumento-símbolo de sus tormentos, como lo había sido el remo para los galeotes». En conclusión, tampoco resulta arriesgado relacionar la etimología de estos cantes con cierto tipo temático de romances narrativos sobre el trabajo forzado con los martinetes, textos peculiares que pueden ser compuestos incluso por los mismos gitanos afectados. Hay que tener en consideración que Del Campo y Cáceres (2013: 462) anotan: «La diferencia principal entre los romances tradicionales y los que dieron lugar a las tonás, es que en estos últimos los protagonistas son los propios gitanos y se narran acontecimientos concretos acaecidos a este pueblo». Estos acontecimientos concretos bien pueden ser los de la Prisión General, «una de las medidas sistemáticas más controvertidas que una monarquía europea proyectó contra un sector de sus propios súbditos» (Martínez, 2014: 5), que los afectados recordarían en romances narrativos y largos.

Suárez Ávila (2010: 292-299) proporciona múltiples ejemplos más de tonás y martinetes narrativos, cantados por sus informantes, sobre las detenciones, los trabajos 
forzados en el Arsenal Marítimo gaditano como principal destino de los detenidos y la persecución en general que sufrieron los gitanos a mediados del siglo XVIII. Este investigador se muestra muy convencido de que, junto a aprovechar las partes seleccionadas de los romances existentes, los recitadores serían capaces de componer los textos, usando los elementos breves para componer nuevos textos largos y adaptados a su situación personal. Es decir, estos textos primitivos de tonás los construyeron los mismos gitanos, mediante la técnica de las fórmulas oral-formulaicas (véase Parry, 1928; Lord, 1960), ya que tendrían un conocimiento perfecto de las fórmulas del romancero medieval épico, del cual eran los más destacados transmisores:

Desde el XVII, he observado, además, que junto al cultivo de los romances y canciones, estos gitanos inauguran una etapa, llamémosle 'aédica'. Al lado de Bernardo del Carpio, de Carlomagno, del Marqués de Mantua, del Conde Grifos Lombardo o del Cid, va naciendo una poesía narrativa que constituye una verdadera epopeya gitana. De su paso por las galeras van dejando, en las tonás, auténticos retazos líricos -¿mejor épicos?-, de sus desdichas. El repertorio conservado es amplísimo y más debió serlo en su tiempo. Constituyen esas coplas lo que Alonso el del Cepillo llamaba 'la memoria de mi gente', cuando, como un león herido, entonaba para sí las tonás que relatan las dramáticas vidas de sus antepasados.

(Suárez Ávila, 2010: 292)

Se puede resumir que los gitanos afectados por las medidas políticas han compuesto con estos romances narrativos sobre la situación en el siglo XVIII una memoria de su pueblo. Esta memoria hoy queda sólo latente en las connotaciones que evocan las melodías y los fragmentos textuales de los martinetes, ya que el contenido textual se ha perdido en su totalidad. Una condición para poder explicar esta pérdida es ubicar la mencionada transformación de los romances preflamencos narrativos en cantes líricos en el contexto del romanticismo. Un objetivo principal de esta aportación, además de comprobar la procedencia romancística de los cantes a palo seco, es señalar que los textos narrativos sobre un hecho histórico concreto, como es la Prisión General de 1749, empezaban a transformarse y convertirse paulatinamente en letras líricas a lo gitano, según las modas de la época siguiente. Estas letras son las que se cantan todavía hoy.

En conclusión, se puede reafirmar que los cantes a palo seco, siguiendo la hipótesis aceptada de su derivación del romancero, son un género preflamenco que se ha transformado en una modalidad musical flamenca con la correspondiente fragmentación de sus letras en coplas breves y líricas. Así, se puede explicar la disminución de la conciencia sobre una narratividad de los textos completos en la memoria flamenca, durante los más de cien años que transcurrieron entre la mitad del siglo XVIII y los finales del siglo XIX en los que el flamenco se había establecido como cultura musical.

\section{REFERENCIAS BIBLIOGRÁFICAS}

Aguilar y Tejera, Agustín. 1998. La Saeta. 2. edición. Sevilla: Portada.

Baltanás, Enrique. 2005. «Introducción». En Cantos populares españoles: Recogidos, ordenados e ilustrados por Francisco Rodríguez Marín, ed. Enrique Baltanás. Sevilla: Renacimiento, pp. IX-XXXIX.

Baltanás, Enrique y Pérez Castellano, Antonio. 1989. «Cómo vive el romancero entre los gitanos de la provincia de Sevilla: Las familias Peña y Fernández». En El Romancero: Tradición y pervivencia a fines del siglo XX, ed. Pedro Piñero. Sevilla: Fundación Machado, pp. 625-636.

Blas Vega, José y Ríos Ruiz, Manuel. 1990. Diccionario enciclopédico ilustrado del Flamenco. 2. ${ }^{\text {a }}$ edición. Madrid: Cinterco. 
Bonet, Soledad y Ruiz Fernández, María Jesús. 1989. «Unas calas en los romances de los gitanos de Jerez». En El Romancero: Tradición y pervivencia a fines del siglo XX, ed. Pedro Piñero. Sevilla: Fundación Machado, pp. 637-645.

Cáceres Feria, Rafael y del Campo Tejedor, Alberto. 2013. «Herreros y Cantaores: El trabajo de los metales en la génesis del flamenco». Revista de Dialectología y Tradiciones Populares, Vol. LXVIII, 2: 445-467.

Cantos Casenave, Marieta. 1996. "Gitanofilia: de algunos rasgos costumbristas del género andaluz». En Actas del VI Congreso: El costumbrismo romántico, ed. VI Congresso sul Romanticismo spagnolo e ispanoamericano. Roma: Bulzoni, pp. $65-70$.

Castaño Hervas, José. 2007. De Jerez y sus cantes. Córdoba: Almuzara.

Castro Buendía, Guillermo. 2010. «Los cantes sin guitarra en el flamenco: antecedentes musicales y modalidades». Revista de Investigación sobre Flamenco La Madrugá, 2: $1-61$.

Cenizo Jiménez, José. 2009. Poética y didáctica del flamenco: una visión interdisciplinar. Sevilla: Signatura.

Cruces Roldán, Cristina. 2004. «Decir el cante: la lírica popular al servicio de la música flamenca». En De la canción de amor medieval a las soleares, ed. Pedro Piñero. Sevilla: Fundación Machado, pp. 599-612.

Díaz-Mas, Paloma. 2008. «El romancero, entre la tradición oral y la imprenta popular». Destiempos, 15: 115-129.

Espejo Arrebola, Juan Antonio. 2011. «Las leyes y el flamenco». Revista de Investigación sobre Flamenco La Madrugá, 4: 21-36.

Fernández Bañuls, Juan Alberto y Pérez Orozco, José María. 2004. La Poesía flamenca, lírica en Andaluz. 2. a edición. Sevilla: Signatura.

Gamboa, José Manuel y Núñez, Faustino. 2007. Flamenco de la A a la Z: Diccionario de términos del flamenco. Madrid: Espasa Calpe.

García Gómez, Génesis. 1993. Cante flamenco, cante minero: Una interpretación sociocultural. Barcelona: Anthropos.

García Lorca, Federico. 1984. «Importancia histórica y artística del primitivo canto andaluz llamado cante jondo». En Conferencias I, ed. Christopher Maurer. Madrid: Alianza, pp. 43-83.

Gómez, Agustín. 2003. Cantes y Estilos del Flamenco. Córdoba: Universidad de Córdoba.

Gómez Alfaro, Antonio. 1993. La gran redada de gitanos: España, la prisión general de gitanos en 1749. Madrid: Centro de Investigaciones Gitanas.

Lefranc, Pierre. En línea. «La génesis de martinete: I». En Jondoweb. https://www.jondoweb.com/contenido-la-genesis-de-martinete-i-746.html [31.03.2020].

Lord, Albert. 1960. The Singer of Tales. Cambridge: Harvard University Press.

Machado y Álvarez, Antonio. 1996. Colección de cantes flamencos: Recogidos y anotados por Demófilo, ed. Enrique Baltanás. Sevilla: Portada.

Martín García, María del Rosario. 2011. «Flamenco de papel». En Investigación y flamenco, ed. José Miguel Díaz-Báñez y Francisco Javier Escobar Borrego. Sevilla: Signatura, pp. 181-192.

Martínez Martínez, Manuel. 2014. Los gitanos y gitanas de España a mediados del siglo XVIII: El fracaso de un proyecto de 'exterminio' (1748-1765). Almería: Universidad de Almería.

Mendoza García, Jorge. 2014. «La configuración de la memoria colectiva: los artefactos». Entreciencias: diálogos en la Sociedad del Conocimiento, 3: 103-119. 
Molina, Ricardo y Mairena, Antonio. 2004. Mundo y formas del cante flamenco, ed. José Cenizo Jiménez. Sevilla: Giralda.

Mora, Joaquín, Gómez, Francisco, Gómez, Emilia, Escobar Borrego, Francisco Javier y Díaz-Báñez, José Miguel. 2010. «Characterization and Melodic Similarity in A Cappella Flamenco Cantes». En Proceedings of the 11th International Society for Music Information Retrieval Conference (ISMIR), ed. J. Stephen Downie y Remco C. Veltkamp. Utrecht: International Society for Music Information Retrieval, pp. 351-356.

Navarro, José Luis y Trigo, José Manuel. 1993. Naranjito de Triana: fiel a sus sentimientos. Sevilla: Castillejo.

Núñez, Faustino. 2011. «Las letras del cante flamenco». En Flamencopolis. http://www.flamencopolis.com/archives/1469 [30.03.2020].

Parry, Milman. 1928. L'Epithète traditionelle dans Homère. Paris: Société d'éditions Les belles lettres.

Piñero Ramírez, Pedro. 2001. «Mozos codiciosos de honra, pero más enamorados: La floración última de la caballería medieval en el romancero fronterizo». En $L a$ eterna agonía del romancero, ed. Pedro Piñero. Sevilla: Fundación Machado, pp. 97-116.

Piñero Ramírez, Pedro, Agúndez García, José Luis, Flores Moreno, Dolores, López Sánchez, José Pedro y Pérez Castellanos, Antonio José. 2013. Romancero de la provincia de Sevilla. Sevilla: Universidad de Sevilla.

Robertson, Sandra. 1989. "La canción de El prisionero en la tradición gitana-andaluza». En El Romancero: Tradición y pervivencia a fines del siglo XX, ed. Pedro Piñero. Sevilla: Fundación Machado, pp. 609-616.

Ruiz Fernández, María Jesús. 2019. «Luces y sombras del cancionero popular infantil». En La voz de la memoria: nuevas aproximaciones al estudio de la Literatura Popular de Tradición Infantil, ed. César Sánchez Ortiz y Aránzazu Sanz Tejada. Cuenca: Universidad de Castilla-La Mancha, pp. 223-243.

Steingress, Gerhard. 2005. Sociología del cante flamenco. 2. ${ }^{a}$ edición. Sevilla: Signatura.

Suárez Ávila, Luis. 2010. «La memoria viva, el olvido y el fragmentismo, poderosos agentes fundacionales del flamenco». Boletín de la Real academia Sevillana de Buenas Letras: Minervae Baeticae, 38: 289-314.

—. 2008. «Flamenco: motivación metonímica y evolución cultural del nombre de los gitanos y de su cante». Culturas Populares: Revista Electrónica, 7: 1-26.

-. 2003. «Reflexiones sobre la tradición atípica: el repertorio romancístico de Antonio Mairena». Revista de Flamencología, 18: 63-92.

—. 1994. «De Bernardo del Carpio a los gitanos bajoandaluces». Insula: Revista de letras y ciencias humanas, 567: 18-20.

—. 1989. «El romancero de los gitanos, germen del cante flamenco». En El Romancero: Tradición y pervivencia a fines del siglo $X X$, ed. Pedro Piñero. Sevilla: Fundación Machado, pp. 563-608.

Vadillo Comesaña, Juan Manuel. 2015. La poesía y el flamenco (de Augusto Ferrán a Luis Rius). Tesis Doctoral. México D.F.: Universidad Nacional Autónoma de México.

Zoido Naranjo, Antonio. 2009. La Ilustración contra los Gitanos: Antecedentes, historia y consecuencias de la Prisión General. Sevilla: Signatura.

—. 2004. «Badulaques, soldados, negros, gitanos... y flamencos: la poesía popular y el origen del término flamenco». En De la canción de amor medieval a las soleares, ed. Pedro Piñero. Sevilla: Fundación Machado, pp. 649-656.

—. 1999. La prisión general de los gitanos y los orígenes de lo flamenco. Sevilla: Portada. 